Voix et Images

volxetimages

\title{
Index du volume XXXI
}

Volume 32, numéro 1 (94), automne 2006

Denis Vanier

URI : https://id.erudit.org/iderudit/014721ar

DOI : https://doi.org/10.7202/014721ar

Aller au sommaire du numéro

Éditeur(s)

Université du Québec à Montréal

ISSN

0318-9201 (imprimé)

1705-933X (numérique)

Découvrir la revue

Citer ce document

(2006). Index du volume XXXI. Voix et Images, 32(1), 169-170.

https://doi.org/10.7202/014721ar

Ce document est protégé par la loi sur le droit d'auteur. L'utilisation des services d'Érudit (y compris la reproduction) est assujettie à sa politique d'utilisation que vous pouvez consulter en ligne.

https://apropos.erudit.org/fr/usagers/politique-dutilisation/
Cet article est diffusé et préservé par Érudit.

Érudit est un consortium interuniversitaire sans but lucratif composé de l'Université de Montréal, l'Université Laval et l'Université du Québec à Montréal. Il a pour mission la promotion et la valorisation de la recherche. https://www.erudit.org/fr/ 


\section{N DEX D U VOLUME XXXI}

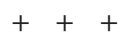

ALLAIRE, Camille, avec la collaboration de Jonathan LAMY, «Bibliographie d'Élise Turcotte», 3, p. 75-84.

ARCHAMBAULT, Gilles, «Inédit. "Préface pour la radio" ", 2, p. 23-29.

BENALIL, Mounia, "De l'orientalisation à la "féminisation du monde" dans Les demoiselles de Numidie de Marie José Thériault», 1, p. 47-60

BENALIL Mounia et Gilles DUPUIS,

«Orientalisme et contre-orientalisme dans la littêrature québécoise», 1, p. 9-13.

BIRON, Michel, «De la compassion comme valeur romanesque», 1, p. 139-146;

«Familles, je vous...», 2, p. 153-158;

"Professeurs d'espoir», 3, p. 129-133.

BONENFANT, Luc, «Jean-Aubert

Loranger. Le miroir occidental de la bibliothèque française», 1, p. 61-74.

BOUVET, Rachel, «Femmes d'Orient, entre paganisme et christianisme. Hypatie selon Jean Marcel», 1, p. 33-45.
BRASSARD, Denise, "Entrer dans le tableau du deuil», 3, p. 9-14; «Entretien avec Élise Turcotte», 3, p. 15-30.

\section{BRAULT, Jacques, «Remarques sur} l'écriture de Gilles Archambault», 2, p. 7184.

BROCHU, André, "Poèmes d'ombre et de lumière», 1, p. 147-151; «Fils déchus et autres matières», 2, p. 159-164; "Aspects de la modernitê"», 3, p. 140-145.

CARON, Pascal, «L'amitiê de Gaston Miron et Henri Pichette», 2, p. 129-146

\section{CARRIÈRE, Marie et Catherine} KHORDOC, "Deuils au pluriel. Sur deux textes d'Abla Farhoud», 3, p. 105-125.

CHARTIER, Daniel, «Avant-propos», 1, p. 5-6; «Avant-propos», 2, p. 5; «Avantpropos», 3, p. 5-6.

CÔTÉ, Nicole, "L'île de la Merci, ou comment éviter le désastre», 3, p. 47-58.

DÉCARIE, David, «Ma langue à toi », 3, p. 156-160.
DION, Robert, «Vie culturelle, vie littéraire », 2, p. 177-182.

DUPUIS, Gilles, «L'Orient désorienté. Le topos du Chinatown dans quatre romans contemporains», 1, p. 101-114.

FACAL, Cécile, «Littérature personnelle et pratiques de lecture. La lecture engagée chez Hector de Saint-Denys Garneau et Fernand Ouellette», 1, p. 117-131.

\section{FORTIER, Frances, «Fiction, diction, et} autres enchantements narratifs», 3, p. 134139.

HANANIA, Cécile, «De Hiroshima à Éroshima. Une érotique de la bombe atomique en forme de haïku selon Dany Laferrière », 1 p. 75-87.

JOUBERT, Lucie, «L'institution faite femme», 1, p. 161-165; «À propos de deux icônes », 2, p. 172-176.

LANDRY, Gabriel «L'(h)au(t)-delà et l'icibas", 1, p. 152-160; «Le lieu et la formule», 2, p. 165-171.

LAFOREST, Daniel, «Du poème au romanesque. L'espace problêmatique de 
l'image dans l'œuvre d'Élise Turcotte», 3, p. 59-73.

\section{LECHASSEUR-PIERRE, Andréanne,}

«Bibliographie de Gilles Archambault», 2, p. $85-104$.

LEQUIN, Lucie, «De la mémoire vive au dire attênué. L'êcriture d'Aki Shimazaki», 1, p. 89-99.

MAILHOT, Laurent, «Romans d'auteur, romans de la mère et du fils», 2, p. 31-47.

MARCOTTE, Sophie, «Une œuvre sousentendue", 2, p. 9-14.
MARCOTTE, Sophie et François RICARD,

«Entretien avec Gilles Archambault», 2,

p. $15-21$

PARÉ, François, «Lectures de l'artisanat »,

1, p. 135-138; «Imbrications du récit contemporain», 2, p. 149-152; "Pluralitê et convergence dans la poésie d’Élise Turcotte», 3, p. 35-45.

RAJOTTE, Pierre, «L'Orient dans les récits des voyageurs québécois de la seconde moitiê du vingtième siècle. Une expérience de déperdition de soi», 1, p. 15-31.

RANDALL, Marilyn, «La disparition élocutoire du romancier. Du "roman de la lecture" au "roman fictif" au Québec ", 3, p. 87-104.

ROBERT, Lucie, «Voyager pour souffrir», 1, p. 166-173; «À l'origine de toutes les origines", 3, p. 146-155.

SAINT-MARTIN, Lori, «Pères et paternité dans l'œuvre de Gilles Archambault », 2 , p. $49-70$.

TURCOTTE, Élise, «Inédit. Cœur sauvage», 3, p. 31-34.

XANTHOS, Nicolas, «Communautés de paroles. La poétique dialogale de Trente Arpents », 2, p. 107-127. 